\title{
AC 2009-320: ACTIVE AND INTELLIGENT MATERIALS: THEORY MEETS APPLICATION
}

\section{John Marshall, University of Southern Maine}

John Marshall received his Ph.D. from Texas A\&M University and is the Internship Coordinator for the Department of Technology at the University of Southern Maine. His areas of specialization include Power and Energy Processing, Applied Process Control Engineering, Automation, Fluid Power, and Facility Planning. 


\section{Intelligent Materials: Theory Meets Application}

The focus of this paper is a "hands-on" activity that was first presented at the National Educator's Workshop. Sponsors of this workshop included the National Aeronautics

\& Space Administration (NASA), the National Institute of Standards and Technology (NIST), and the American Society for Engineering Education (ASEE). One of the objectives of this workshop is to provide educators with material activities that they may wish to include in their curriculums. The required format for these material activities is: Introduction; Current Applications; Method of Operation; Summary; Student Activity; Outcomes and Post-Lab Analysis; Sources of Supplies; and then the Activity Procedure.

During the Annual ASEE Conference, selected material activities are presented during a specialized technical session dedicated specifically for these workshop activities. A magneto-rheological fluid device will be available, and all participants are invited to work with this incredible material.

\section{Learning Objectives}

As a result of this lesson and activity, participants will be able to:

Discuss the basic concepts of intelligent materials and explain why magnetorheological (MR) fluids are included in this category.

Identify current applications of MR fluids, focusing on the performance enhancing benefits.

Relate MR fluid's method of operation, characteristics, and potential applications.

Discuss the "tunable" advantage of power transmission systems that results from the proportional state change of MR fluids.

\section{Curriculum Integration}

Intelligent materials are an interesting material that students find fascinating and thought provoking. The purpose of this document to provide teachers and students with a baseline knowledge, and an opportunity to physically work with one of these innovative substance. MR fluids have served as topics in a variety of curriculums. In fluid power courses such as hydraulics, MR fluids have the potential to revolutionize the "valve" component that currently relies on interfacing electro-mechanical devices. 
In applied process control engineering curriculums, such as programmable logic controllers, MR fluids are easily activated and deactivated by controllers to maintain process set points. Using these fluids in conjunction with proportional-integralderivative programming accurately removes hysteresis effects on the process being controlled. In statics and dynamics curriculums, sheering force calculations during fluid transitions provides remarkable insight into the clutching and dampening capabilities of the fluid.

\section{Introduction}

Magneto-rheological (MR) fluids are a form of "intelligent" material that change their flow characteristics when subjected to a magnetic field. Response, which takes only milliseconds, is in the form of a progressive gelling that is proportional to field strength. MR fluids can be produced that are capable of giving high shear stresses at low applied magnetic fields. The unique nature of this class of magnetic fluids allows dramatic changes in rheology to occur within the bulk of the fluid on application of a relatively modest magnetic field. The material can change from being fluid to solid almost instantaneously, the rheology of the material reverting to its original state upon removal of the field.

"Response, which takes only milliseconds, is in the form of a progressive gelling that is proportional to field strength. With no field present, the fluid flows as freely as hydraulic oil".' As a result, MR technology provides fast and infinitely variable control of energy dissipation of industrial and automotive devices. ${ }^{2}$ This change of state has the potential to revolutionize the control aspects of vibration and the responsiveness of hydraulic power transmission systems. "The application of magneto-rheological fluids for damping is a unique and novel approach to an age-old problem". 3

MR fluids have existed for over fifty years. However, it is only now that fluids are available that are stable and give shear stresses that are adequate in demanding applications such as automotive damping. In fact, one automotive manufacturer is equipping several of its new (2007) vehicles with a "MagneRide Suspension" that utilizes MR fluid technology. The manufacturer claims that the MagneRide suspension provides continuous variable real-time suspension damping based on road and driving conditions. ${ }^{2}$ 


\title{
Current Applications
}

The Lord Corporation, located in North Carolina, is one of the major suppliers of MR fluids. They offer a very logical method of categorizing MR fluids by their current market segment and their specific applications. ${ }^{4}$

\author{
Automotive \\ Primary Suspension \\ Passenger Protection \\ Knob \& Detent \\ Clutch \\ Military \& Defense \\ Primary Suspension \\ Passenger Protection \\ Clutch \\ Seat Suspension \\ Tactile Feedback Device \\ Off-Highway \& Con/Ag Vehicles \\ Primary Suspension \\ Secondary ( $\mathrm{Cab})$ Suspension \\ Passenger Protection \\ Knob \& Detent \\ Clutch \\ Seat Suspension \\ Civil Engineering \\ Seismic Protection \\ Cable-Stayed Bridges \\ Industrial \\ Washing Machine \\ Medical \\ Prosthetic Joint
}

Let's take a closer look at some of these interesting applications:

MR fluid is providing new levels of performance in vehicle primary suspension systems. These systems provide real-time optimization of suspension damping characteristics that improve ride and handling. This high-technology suspension is available now on Cadillac, Corvette, and Buick automobiles. Several more automakers will be announcing their MR fluid based suspension applications for the 2008 model year. ${ }^{5}$ 
MR suspensions are not limited to commercial automobiles. MR suspensions can deliver great benefits to military vehicles, including improvement in maneuverability and safe driving speed, reduced risk of roll-over, reduction in driver absorbed power/fatigue, and reduction in vehicle wear-and-tear due to up-armoring. MR fluid has been used in successful demonstrations of MR technology on Humvees and a Stryker. Similar benefits can also be realized in non-military off-highway applications.

The tactile feedback device is a cost-effective and design-efficient feedback solution for improving "by-wire" control and safety. Unlike electric-motor feedback devices, which can transmit unwanted and potentially hazardous forces to the operator, MR fluid based devices produce a continuously variable resistive steering torque, delivering high-fidelity "feel" and maximum control to the operator. A leading forklift manufacturer uses a MR fluid based device to provide tactile feedback for its steer-by-wire reach trucks. Replacing the hydraulic steering system with a steer-by-wire system enabled a lighter vehicle with a smaller footprint and fewer parts. It also reduced electricity usage and extended the battery life, while improving the quality of steering "feel". 6

The knob and detent application is being used to provide locking and resistance in control knobs and detent devices. Differing tactile sensations for different functions/modes leads to more efficient, multiple-use controls. MR technology can be used to provide infinitely variable detents in door $\&$ hatch hinges and dampers. These detents can be programmed to vary according to various criteria (e.g., incline of vehicle). The technology provides greater longevity in locking raised hatches than traditional hydraulic shocks. ${ }^{7}$

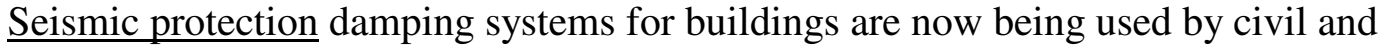
architectural engineers. The MR fluid devices enlarge the control envelope of baseisolation and distributed-damping systems that protect against earthquakes - against both initial shocks and aftershocks. ${ }^{7}$

Civil and architectural engineers are protecting cable-stayed bridges with MR fluid devices. These fluid dampers attached to cables provide a continuously controllable, cost-effective solution to wind-rain-induced cable "gallop." 9

MR fluid technology is now being applied to industrial washing machines and other appliances to decrease the noise and vibration. The controllable nature of the fluid allows fine tuning to match the different levels of vibration that occur during different wash/spin cycles. ${ }^{10}$

A German manufacturer of prosthetic joints has developed a device that improves the mobility of above-the-knee leg amputees. The device increases gait balance, stability and energy efficiency using controllable MR fluid technology. The responsiveness and the controlled resistance of the fluid allows the prosthetic joint to emulate natural movements. ${ }^{11}$ 


\section{Method of Operation}

The method of operation for MR fluid is very simple. Magneto-rheological fluids are composed of two primary components. They are the carrier fluid and the suspended particles. "The carrier fluid needs to be a good insulator, compatible with the materials they contact. Typical particle materials include polymers, minerals, and ceramics". ${ }^{12}$

When a magnetic field is applied to the MR fluid, positive and negative charges on the particles respond by separating, so each particle then has a positive end and a negative end. Particles of the magneto-rheological fluid then "link together in the same manner that the north pole of one magnet is attracted to the south pole of another magnet". 13

MR fluids can activate from solids to liquids so fast, they will work well with fast-acting computers. "These characteristics suggest a number of unusual engineering applications such as fluid clutches and vibration isolators". ${ }^{13}$ According to J. David Carlson of the Lord Corp, "A good example of unwanted vibratory motion is a washing machine in its spin cycle trying to walk out of the room. MR damping can correct this and other problem vibrations".

14 A professor of materials science and engineering at North Carolina State University also feels that "magneto-rheological fluids will lead to a whole new generation of brakes, automatic transmissions, actuator devices, hydraulic valves, pump parts, and motors". 15

"MR fluids are usually applied in one of two modes. MR fluid operating in valve mode, with fixed magnetic poles, may be appropriate for hydraulic controls, servo valves, dampers, and shock absorbers. The direct-shear mode with a moving pole, in turn, would be suitable for clutches and brakes, chucking/locking devices, dampers, breakaway devices and structural composites" (including images on next page). ${ }^{16}$
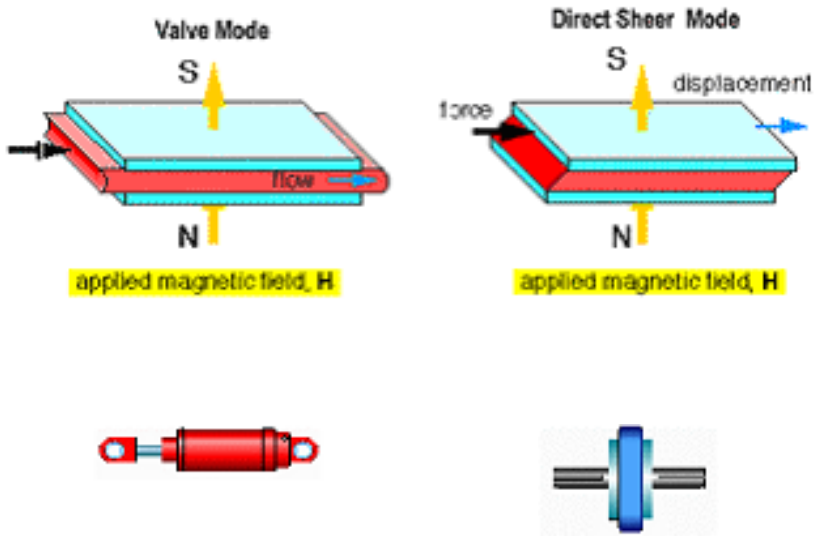

Hydraulic controls

Clutches \& brakes

Servo valves

Dampers

Shock absorbers

Actuators

Chucking/locking devices

Dampers

Breakaway devices

Structural composites 


\section{Summary}

In addition to the current applications identified above, MR fluids have the potential to revolutionize robotics and industrial automation by widening the performance range of electromechanical and electrohydraulic equipment. Current automation capabilities are not advanced enough to build a robot that could catch a ball. Even though cameras and computers could direct the robot towards the ball, robot's move in an awkward, lumbering fashion because conventional hydraulic valves cannot keep pace with the commands of the computerized controllers.

MR fluid, can "cycle" at a rate of 200 times per second. As a result, this technology will allow devices that can operate instantly and without mechanical valves. Increased productivity and better product quality through more dependable and responsive automated equipment is just a small part of what this maturing technology can deliver.

The presentation will be followed by an actual demonstration of the material experiment and an opportunity for participants to actively engage this extraordinary substance.

\section{Student Activity}

This activity will be useful to students studying material technology as well as those involved in industrial power transmission, automation, and process control. Students with just a cursory understanding of magnetism will find the concept of state change within a material, based on a magnetic field, fascinating and can serve as a basis for a more advanced investigation into magnetism and materials. Those students who have insight into industrial power transmission systems (electrical, mechanical, hydraulic, and pneumatic) and process control technologies (programmable logic controllers, etc.) will see the enormous advantages this technology has to offer over traditional methods.

\section{Outcomes and Post-Lab Analysis}

A suggested post-lab analysis would be to contrast response times and "mean times between failures" from a traditional power and control system, to one that utilizes magneto-rheological fluids.

Even though hydraulics has the highest power to weight ratio of any industrial power transmission system, the mechanical servo valves and directional controls valves are very weak links. Because they are mechanical components, they cannot keep-up with the speed of computer/controller commands. Control valves are a primary source of equipment down-time, and a major contributor to heat generation and system contamination. 
Conclusions one may reach during a post-lab analysis may focus of the superior characteristics of MR fluid and their potential to increase efficiencies and performances in the next generation of equipment. Highly controllable, fast acting and no moving parts makes this technology an intersting engineering activity.

\section{Source of Supplies and Specific Hardware Information}

Many different suppliers offer products that can be used to accomplish this activity. The website identified below has many links to suppliers as well as video clips, magnetorheological material specifications, and images of current applications. An email address and telephone number is also provided. mrfluid@lord.com 1-919-469-2500, ext. 2150.

http://www.lord.com/

\section{Procedure}

Safety Considerations:

1. Protective eye wear is mandatory for all those in the lab area.

2. Read the operating instructions that accompany the active magneto-rheological clutch assembly and power supply.

3. Obtain a "Material Data Safety Sheet" on the fluid from the supplier. Read the sheet completely and ask questions to any information you do not understand.

Observing the tunable clutch assembly:

1. With the power supply off, notice how easily the shafts can be rotated by hand.

2. Increase the power output through the range of $4,8,16,32,60$, and $80 \%$ and record your findings on the data sheet.

3. Vary the cycling frequency through the range of $4,8,16$, and $32 \mathrm{~Hz}$ and notice the pulsating sensation while rotating the shafts. Record your findings on the data sheet. 


\section{Sample Data Sheet A}

Record the characteristics of the clutch when varying the power output.

\begin{tabular}{|l|l|}
\hline $4 \%$ & \\
\hline $8 \%$ & \\
\hline $16 \%$ & \\
\hline $32 \%$ & \\
\hline $60 \%$ & \\
\hline $80 \%$ & \\
\hline
\end{tabular}

\section{Sample Data Sheet B}

Record the characteristics of the clutch when varying the cycling frequency.

\begin{tabular}{|l|l|}
\hline $4 \mathrm{~Hz}$ & \\
\hline $8 \mathrm{~Hz}$ & \\
\hline $16 \mathrm{~Hz}$ & \\
\hline $32 \mathrm{~Hz}$ & \\
\hline
\end{tabular}

\section{Instructor Notes}

1. The power being transmitted through the clutch increases proportionally when the power output is increased.

2. The impulses of power transmission increase as the cycling frequency is increased. 


\section{Bibliographic Information}

1. Korane, K.: Putting ER Fluids To Work. Machine Design, May 9,1991, pp. 52-57.

2. Audi to Unveil Magneride Semi-Active Suspension System Enabled by MR Fluid Technology, Fluid Power Journal, November/December 2006, p12.

3. Southoff, Clark, Technology Wranglers Inc., Sensor Technology and Design, February 2002, http://www.sensorsmag.com/articles/0202/30/main.shtml.

4. Lord Corporation, Industry Knowledge Leads to Innovative Solutions, Applications, downloaded January 2007, http://www.lord.com/tabid/3327/Default.aspx.

5. Lord Corporation, Industry Knowledge Leads to Innovative Solutions, Primary Suspension, downloaded January 2007, http://www.lord.com/tabid/3329/Default.aspx

6. Lord Corporation, Industry Knowledge Leads to Innovative Solutions, Tactile Feedback, downloaded January 2007, http://www.lord.com/tabid/3335/Default.aspx

7. Lord Corporation, Industry Knowledge Leads to Innovative Solutions, Knob and Detent, downloaded January 2007, http://www.lord.com/tabid/3331/Default.aspx

8. Marshall, J. (2007). Magneto-rheological Fluids Revolutionizing Power and Control Systems American Society for Engineering Educators, June, 2007.

9. Lord Corporation, Industry Knowledge Leads to Innovative Solutions, Cable-Stayed Bridges, downloaded January 2007, http://www.lord.com/tabid/3355/Default.aspx

10. Lord Corporation, Industry Knowledge Leads to Innovative Solutions, Industrial Washing Machines, downloaded January 2007, http://www.lord.com/tabid/3356/Default.aspx

11.Lord Corporation, Industry Knowledge Leads to Innovative Solutions, Prosthetic Joints, downloaded January 2007, http://www.lord.com/tabid/3358/Default.aspx

12. Scott, D.: Amazing Hardening Fluids Open a New World of Hydraulic Drives. Popular Science, April 1984, pp. 42-46.

13. Duclos, T.G.: Electrorheological Fluids and Devices. Automotive Engineering, December 1988, pp.4548.

14. Carlson, J. D., Lord Corporation, Sensor Technology and Design, February 2002 http://www.sensorsmag.com/articles/0202/30/main.shtml.

15. Conrad, H.: The Impact of ER Fluids. Compressed Air Magazine, March 1992, pp.14-17. http://www.lord.com/tabid/3318/Default.aspx

16. Lord Corporation, Industry Knowledge Leads to Innovative Solutions, MR Fluid Technology, downloaded February 19, 2007, http://www.lord.com/tabid/3318/Default.aspx. 